\title{
Evaluación radiológica de catéteres en UCI neonatal
}

\author{
I. Fuentealba • A. Retamal • G. Ortiz・M. Pérez
}

\begin{abstract}
Radiographic assessment of catheters in a neonatal intensive care unit (NICU)

Intravascular catheters are widely used in Neonatal Intensive Care Units. The major types of intravascular access in the newborn are peripheral catheters, venous or arterial umbilical catheters, central venous catheters and peripherally-inserted central venous catheters (PICC). Anomalous positioning of catheters, especially umbilical catheters, is quite frequent as their installation is without imaging guidance. The radiographic assessment of the catheter performed by pediatricians and/or radiologists, who must be able to recognize those poorly positioned as they can cause serious complications, is essential. This article contains a sample of correct and misplaced catheter $\mathrm{x}$-ray often used in a NICU.
\end{abstract}

(Key words: Umbilical catheters, central venous catheter, catheter complications).

Rev Chil Pediatr 2014; 85 (6): 724-730

\section{RESUMEN}

Los catéteres intravasculares son ampliamente utilizados en las Unidades de Cuidado Intensivo Neonatal. Dentro de los métodos de acceso intravascular en el RN se incluyen catéteres periféricos, catéteres umbilicales arteriales o venosos, catéteres venosos centrales y catéteres venosos centrales de instalación periférica (CCIP). Las posiciones anómalas de los catéteres, especialmente de los catéteres umbilicales son frecuentes ya que su instalación no es guiada por imágenes. Dado lo anterior es muy importante la evaluación radiológica de control de los catéteres que realizan los médicos pediatras y/o radiólogos, quienes deben ser capaces de reconocer aquellos mal posicionados ya que pueden causar complicaciones graves. Este artículo contiene una muestra pictográfica de radiografías de catéteres de uso frecuente en UCI Neonatal, bien y mal posicionados.

(Palabras clave: Catéteres umbilicales, catéter venoso central, complicaciones de catéteres).

Rev Chil Pediatr 2014; 85 (6): 724-730

Recibido el 28 de octubre de 2013. Última versión aceptada el 13 de noviembre de 2014.

Isabel Fuentealba T. $(\bowtie)$

Radiólogo Pediátrico. Clínica Alemana Santiago- Hospital Luis Calvo Mackenna.

E-mail: ifuentealba@alemana.cl

Andrés Retamal C.

Residente Radiología. Clínica Alemana-Universidad del Desarrollo.

Guillermo Ortiz C.

Interno Medicina. Universidad de Chile.

Marcela Pérez R.

Neonatóloga, Clínica Alemana Santiago. 


\section{Introducción}

La instalación de catéteres intravasculares es el procedimiento invasivo más frecuente en las unidades de cuidados intensivo neonatal (UCIN $)^{1}$ ya que la terapia endovenosa juega un rol fundamental en el cuidado del Recién Nacido ( $\mathrm{RN}$ ) enfermo, de término o pretérmino. Dentro de los métodos de acceso al intravascular en el RN se incluye catéteres periféricos, catéter umbilical arterial o venoso, catéter venoso central y catéter venoso central de instalación periférica (CCIP). Habitualmente es el médico tratante y/o radiólogo quienes deben evaluar y verificar el correcto posicionamiento de cada uno de los catéteres, sobre la base del conocimiento anatómico normal.

Los objetivos de este artículo son revisar anatomía vascular normal en período fetal y neonatal, identificar en radiografías simples el adecuado posicionamiento de los catéteres, y reconocer mal posicionamiento y/o complicaciones precoces.

\section{Anatomía de los vasos umbilicales}

Las venas umbilicales se originan de las vellosidades coriónicas y transportan sangre oxigenada al embrión, la derecha desaparece alrededor de la sexta semana de gestación de modo que la vena umbilical izquierda es la única que transporta sangre de la placenta al hígado $^{2}$. Esta vena umbilical única se extiende desde el ombligo hasta la vena porta izquierda. Inmediatamente antes de llegar a la porta, la vena umbilical presenta una dilatación llamada receso umbilical ${ }^{3}$. Desde la porta izquierda y opuesto a la llegada de la vena umbilical se origina el conducto venoso que se dirige hacia cefálico hasta la vena cava. Posterior al nacimiento, el conducto venoso en el niño se convierte en el ligamento venoso del hígado y la vena umbilical forma el ligamento redondo ${ }^{2,3}$.

Las arterias umbilicales son ramas ventrales de las aortas dorsales que durante la cuarta semana, cada una establece una conexión con la rama dorsal de la aorta originando las arterias iliacas primitivas. Después de nacer las porciones proximales de las arterias umbili- cales persisten en forma de la arterias iliacas internas y vesical superior y la porción distal se oblitera y forman el ligamento umbilical medio $^{2}$.

\section{Aspecto normal de los catéteres umbilicales en la radiografía}

Los catéteres umbilicales son fácilmente diferenciables en la radiografía tóraco -abdominal. El catéter umbilical venoso (CUV) presenta un trayecto ascendente desde la región umbilical hacia el hígado donde se curva ligeramente hasta alcanzar la vena cava inferior o la unión de la vena cava con aurícula derecha. En la proyección lateral adquiere una forma de "s" atravesando el hígado antes de alcanzar la cava inferior ${ }^{4}$. Por su parte, el catéter umbilical arterial (CUA) inicialmente se dirige desde el ombligo a la pelvis hasta alcanzar la arteria iliaca derecha o izquierda y para luego ascender por la aorta (Figura $1 \mathrm{a}-\mathrm{b}$ ).

La correcta posición de la punta del CUV es en el extremo más cefálico de la vena cava inferior (VCI), en la unión de la VCI con la aurícula derecha $(\mathrm{AD})^{3}$.

Para el CUA se recomienda una de 2 posiciones; entre D6 y D10 sobre el origen del tronco celíaco, o en posición baja entre L3 y L5 sobre la bifurcación de la aorta pero por debajo del nacimiento de las ramas aórticas principales. Un metanálisis demostró que la posición alta del catéter umbilical arterial cuya punta se sitúa sobre el diafragma tiene baja incidencia de complicaciones en comparación con la posición baja ${ }^{5}$. En general se recomienda que el catéter finalice alejado de los principales vasos aórticos, para ello es importante conocer que: el tronco celíaco se sitúa en D12, la arteria mesentérica superior en D12-L1, la arteria renal en L1-L2 y la arteria mesentérica inferior en L3 y bifurcación aórtica en L44.

\section{Mal posición de catéteres umbilicales}

Las posiciones anómalas de los catéteres umbilicales son frecuentes ya que su instalación no es guiada por imágenes ${ }^{3}$. La mal po- 

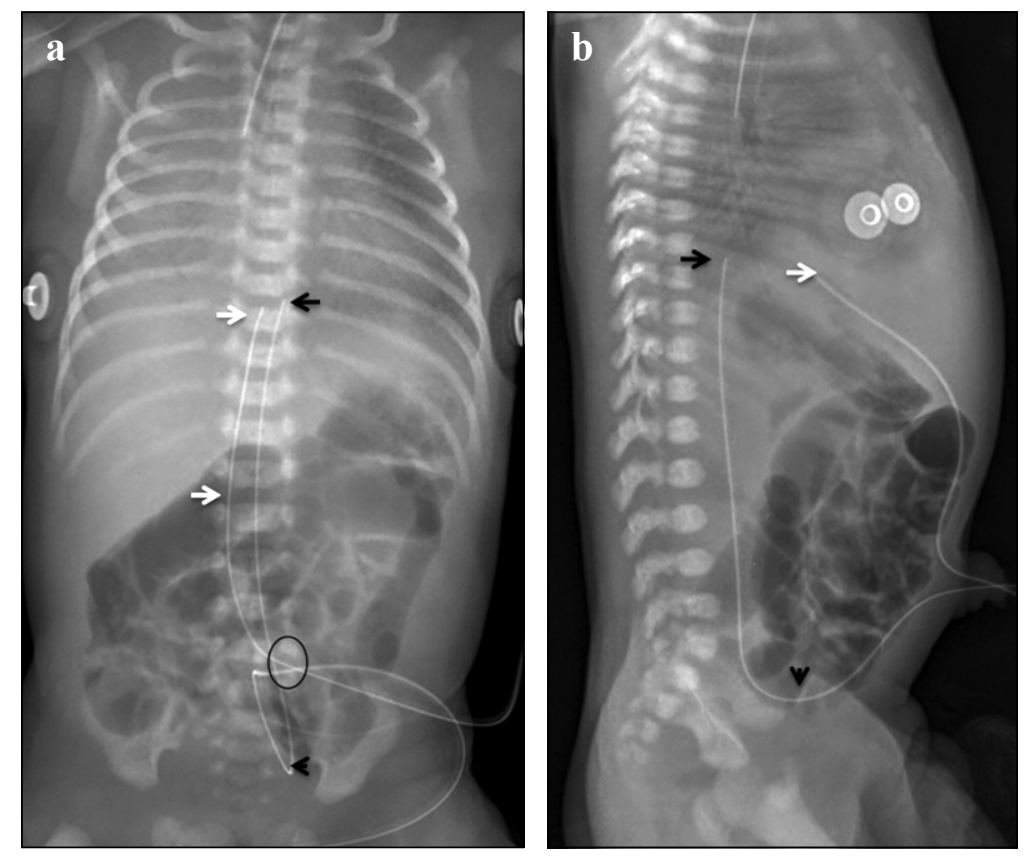

Figura 1. Apariencia normal del catéter umbilical venoso y arterial en radiografía. a) Proyección frontal: CUV entra a nivel del ombligo (circulo negro) luego asciende cefálico en dirección de la vena umbilical a través del hígado hasta alcanzar la vena cava inferior o región distal de la aurícula derecha (flecha blanca), mientras que el CUA baja (cabeza de flecha negra) hasta alcanzar la arteria iliaca izquierda para luego ascender por la aorta hasta nivel de D9; b) Proyección lateral el CUV tiene un trayecto anterior en el abdomen a través del hígado (fecha blanca) hasta su llegada vena cava inferior y el CUA baja hasta la pelvis (cabeza flecha negra) y luego asciende paralelo a la columna vertebral a través de al aorta hasta nivel de D9.
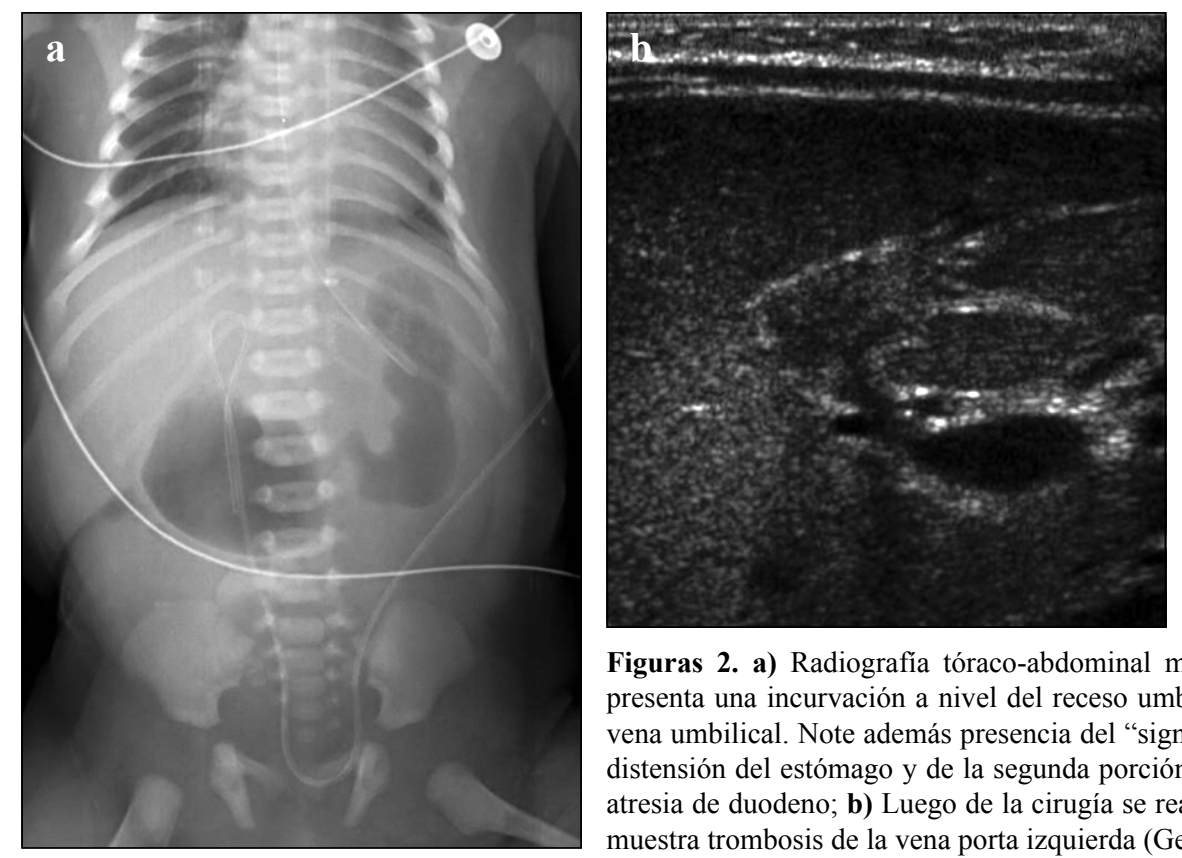

Figuras 2. a) Radiografía tóraco-abdominal muestra catéter venoso que presenta una incurvación a nivel del receso umbilical y se devuelve por la vena umbilical. Note además presencia del "signo de la doble burbuja" con distensión del estómago y de la segunda porción del duodeno secundario a atresia de duodeno; b) Luego de la cirugía se realizó ecografía doppler que muestra trombosis de la vena porta izquierda (Gentileza Dra. Gloria Soto).

sición del CUV se puede producir antes de llegar a la posición deseada y lo podemos encontrar localizado en el receso umbilical antes de llegar a la vena porta izquierda y al tratar de avanzar el catéter se puede devolver en la vena umbilical ${ }^{3,4}$ (figuras 2 a y 2 b). Cuando el caté- ter llega al receso umbilical debe pasar a través de la porta izquierda hacia el conducto venoso, sin embargo, en este punto se puede desviar hacia porta izquierda (figura 3 ) o a la porta derecha (figura 4) o incluso a la porta principal y de ahí puede pasar a la vena mesentérica su- 


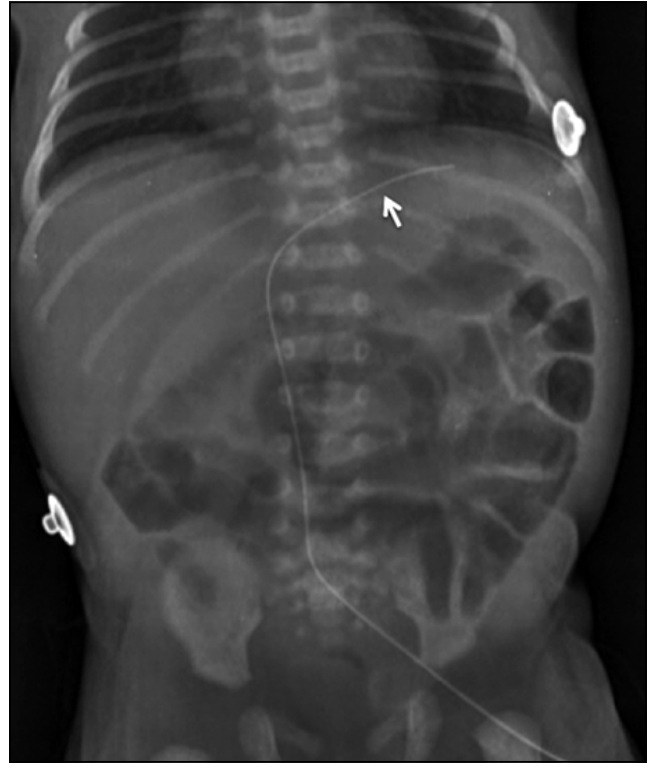

Figura 3. Catéter umbilical venoso en vena porta izquierda. Radiografía de abdomen muestra catéter umbilical venoso que asciende por la vena umbilical y al llegar a la porta se desvía a izquierda en el hígado quedando en la porta izquierda (flecha blanca).

perior y esplénica. El catéter en la porta puede producir trombosis portal ${ }^{6}$. La complicación más tardía y consecuencia de esta última es la cavernomatosis portal e hipertensión portal. También se han descrito hematomas hepáticos y neumatosis portal secundaria.

Otra posición inadecuada del CUV es su llegada en forma errónea hasta la aurícula izquierda vía foramen oval (figura 5), vena pulmonar, aurícula derecha, vena cava superior, yugular interna o ventrículo derecho vía válvula tricúspide.

La posición de la punta del catéter en la aurícula derecha ha sido discutida ampliamente en la literatura ya que existe riego de perforación cardíaca con subsecuente derrame pericárdico y taponamiento cardíaco. También esta descrito que puede inducir arritmias ${ }^{6}$.

En el último tiempo han aparecido algunas experiencias que describen el uso de Ultrasonido para identificar la ubicación de la punta del CUV con buenos resultados. Es una técnica que requiere profesionales con entrenamiento especifico en el área, es relativamente

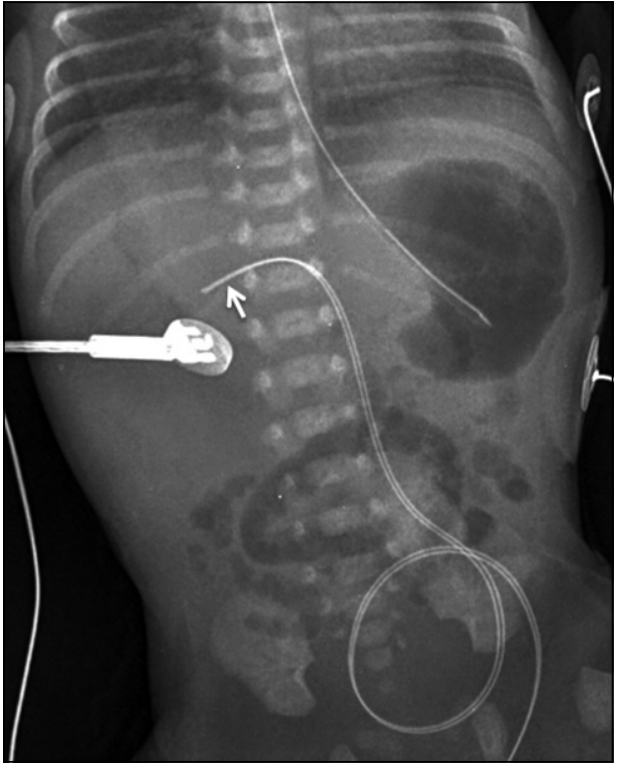

Figura 4. Catéter umbilical venoso en vena porta derecha. Radiografía de abdomen muestra catéter umbilical venoso que llega vía vena umbilical a la vena porta y no asciende por el conducto venoso hacia la vena cava si no que se dirige a la derecha y se introduce en la vena porta derecha.

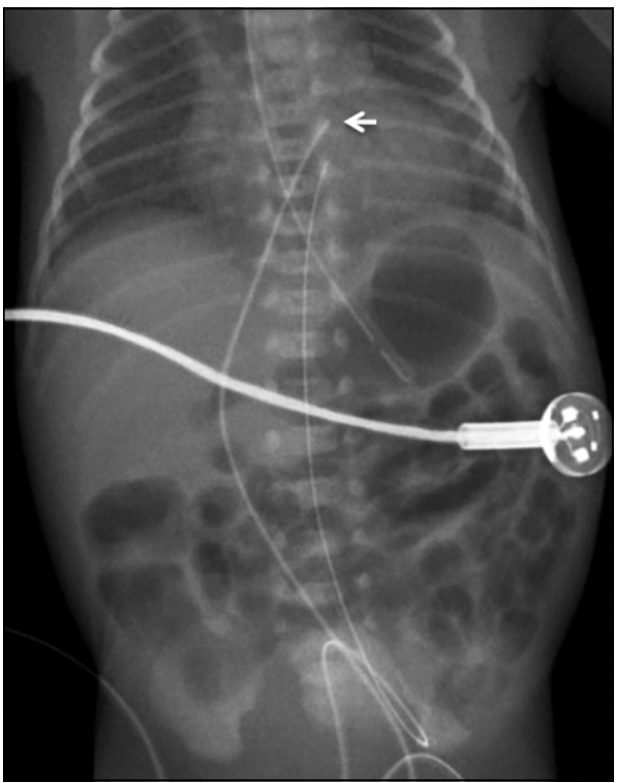

Figura 5. Catéter umbilical venoso insinuado en aurícula izquierda a) proyección frontal toraco abdominal RN pretérmino cursa con Enfermedad por déficit de surfactante. La punta del catéter umbilical venoso cruza el septo interauricular a través de foramen oval y se encuentra insinuado en aurícula izquierda. 
rápida y con la ventaja que es un examen que no irradia ${ }^{7}$.

El CAU puede quedar malposicionado en la arteria femoral, arteria glútea, arterias renales y arteria mesentérica, con riesgo potencial de secuelas graves en algunos casos dentro de los cuales se describe necrosis gluteoperonea asociada a parálisis del nervio ciático secundario a trombosis de la arteria glútea inferior ${ }^{1}$.

\section{Catéter venoso central}

En neonatos se instala catéteres venosos centrales y catéteres venosos centrales de instalación periférica (CCIP), estos últimos se introducen a través de en una aguja de calibre superior insertada en una vena periférica, hasta alcanzar un vaso central. Si ingresan por las extremidades superiores el extremo distal se debe ubicar en la vena cava superior y si ingresa por las extremidades inferiores en vena cava inferior. Dentro de las complicaciones graves que se han descrito en el uso de los CCIP es el taponamiento cardíaco secundario a perforación de la aurícula derecha, el cual puede tener consecuencias fatales sin oportuno diagnóstico y tratamiento. El factor de riesgo para que esto ocurra al igual que CUV es instalar la punta del catéter en el interior de la aurícula, por lo anterior muchos grupos no recomiendan dejar el extremo distal de los catéteres venosos en las cámaras cardíacas ${ }^{6,8,9}$. En estudios de autopsias de niños fallecidos por taponamiento cardíaco, se ha encontrado perforación con y sin necrosis de la pared del miocardio, incluso algunos casos no se ha detectado perforación. Por esta razón se postula que una constante erosión de la punta del catéter en el endocardio de la fina pared de la aurícula derecha, puede producir inflamación con necrosis y/o trombosis con perforación que puede auto-sellar o puede haber difusión de fluidos hiperosmolares que traspasan el endocardio y miocardio dañado ${ }^{1}$. Otro factor de riesgo de perforación de la aurícula derecha adicional a dejar el catéter en su interior es que la punta del catéter presente una curvatura, angulación o incurvación sobre si mismo ${ }^{8}$.

Otras posibles posiciones incorrectas de la punta del catéter son la vena yugular interna (figura 6), foramen oval, aurícula izquierda (figura 7 a y b), vena cava inferior (figura 8), entre otras.

Cuando el CVC ingresa por las extremidades inferiores puede inadvertidamente ascender por la vena lumbar inferior. En la placa de abdomen AP el catéter pareciera estar sobreproyectado en venas iliacas o en vena cava inferior, pero en la placa lateral el catéter se proyecta hacia posterior sobre el canal raquídeo. Cuando no se reconoce esta posición anómala del catéter puede conducir a complicaciones neurológicas graves. Desde el punto de vista clínico algunos pacientes presentan síntomas inespecíficos tales como letargia, desaturación de oxígeno y/o incluso pueden convulsionar. En la punción lumbar se obtiene líquido cefalorraquídeo de aspecto "lechoso", con elevación de la glucosa y los triglicéridos, lo cual se encuentra en relación con la composición de la nutrición parenteral administrada ${ }^{1}$. La vena lumbar ascendente drena al plexo venoso vertebral hacia la vena iliaca común y puede ser fácilmente cateterizada vía femoral o safena interna, especialmente el lado izquierdo porque el ángulo formado entre la vena lumbar ascendente y la vena iliaca común es menos agudo que el ángulo que se forma a derecha ${ }^{1,10}$.

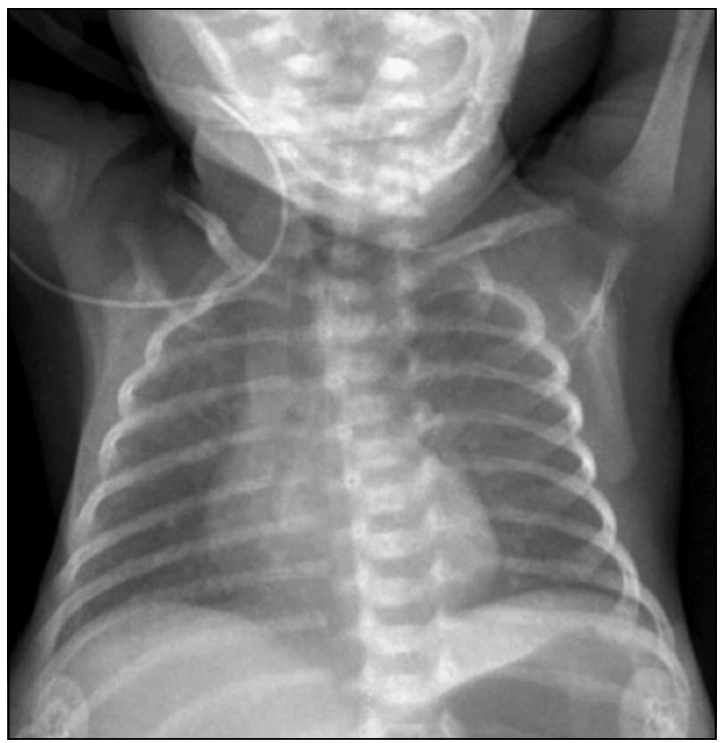

Figura 6. Catéter venoso central vía subclavia derecha que asciende por vena yugular interna derecha. 

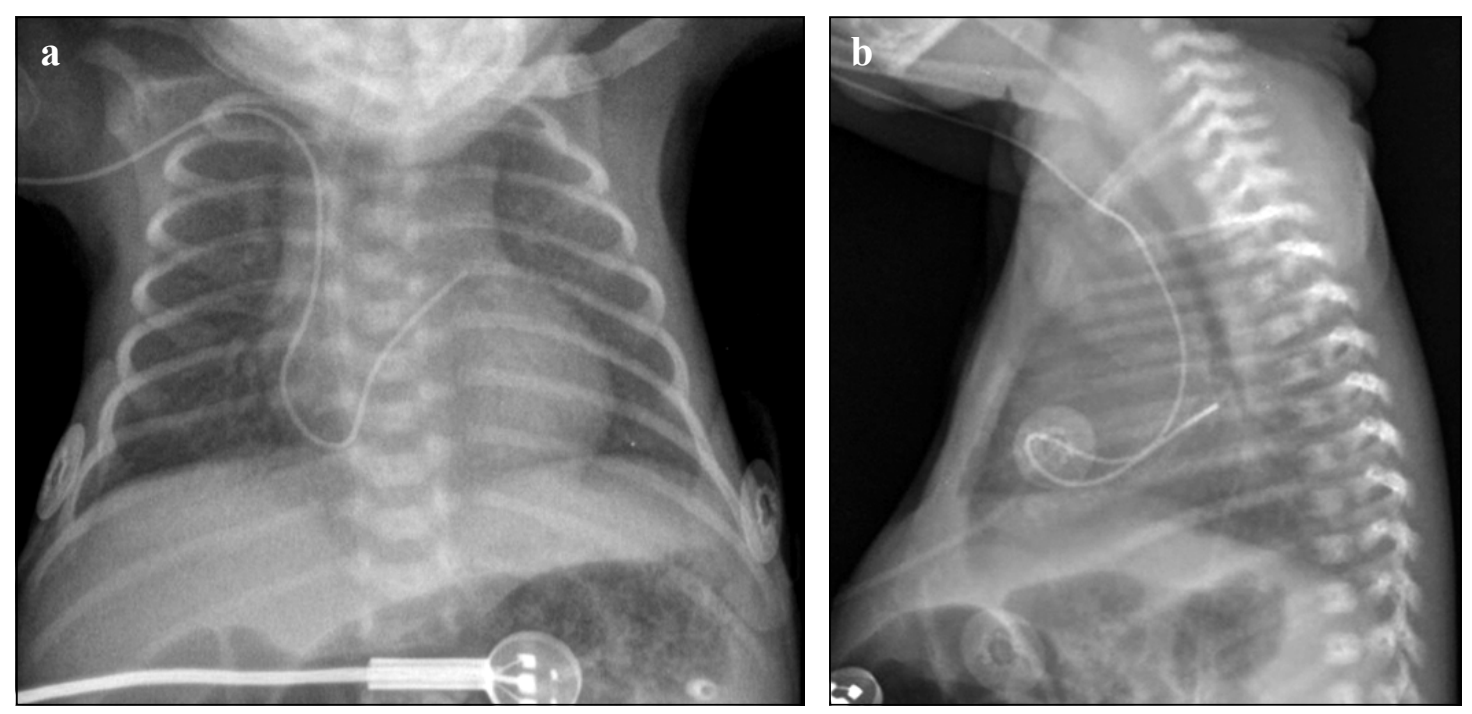

Figura 7. Catéter venoso central vía subclavia derecha ingresa vena cava llega aurícula derecha cruza el septo interauricular a tráves de comunicación interauricular y llega hasta la aurícula izquierda (a); en la proyección lateral (b) se hace más evidente la punta del catéter sobreproyectada hacia posterior en la aurícula izquierda.

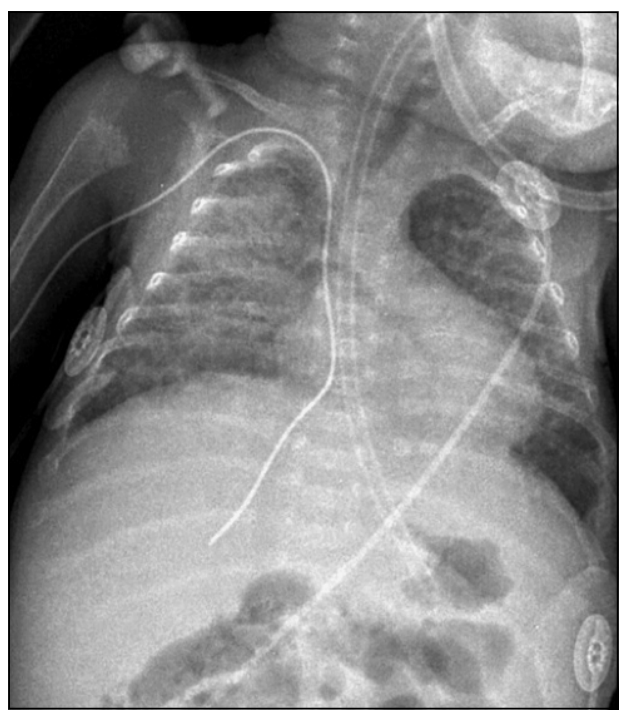

Figura 8. Catéter venoso central de inserción periférica. RN con displasia broncopulmonar que cursa con neumonía. Catéter venoso que avanza desde la vena cava pasa a través de la aurícula derecha llega a vena cava inferior y se introduce en una vena suprahepatica del hígado.

\section{Conclusión}

El examen radiológico sigue siendo en nuestro medio el principal instrumento para controlar la posición de los catéteres. El mal posicionamiento de catéteres se asocia a complicaciones que deben ser prevenidas mediante el reconocimiento precoz por el médico tratante y/o radiólogo. Es necesario estar familiarizado con las imágenes de las recomendaciones de la posición esperada de los distintos catéteres y también de aquellos que adquieren posiciones anómalas.

Potenciales conflictos de interés: Este trabajo cumple con los requisitos sobre consentimiento/asentimiento informado, comité de ética, financiamiento, estudios animales y sobre la ausencia de conflictos de intereses según corresponda.

\section{Referencias}

1.- Ramasethu J: Complications of Vascular Catheters in the Neonatal Intensive Care Unit . Clin Perinatol 2008; 35: 199-222.

2.- Langman L: Embriología médica $4^{\circ}$ edición. Editorial Médica Panamericana. Capítulo: Cardiovascular; Sistema arterial, página 239.

3.- Schlesinger A, Braverman R, DiPietro M: Neonates and Umbilical Venous Catheters: Normal Appearance, Anomalous Positions, Complications, and Potential Aid to Diagnosis. AJR 2003; 180: 1147-53.

4.- Serrano C, Gilabert A, Solís I, Valero F, Torres C, 
Puerta A: Evaluación de catéteres en UCI neonatal: El papel del radiólogo y hallazgos en imagen de sus complicaciones. http://www.seram2008.com/modules/ posters/files/poster.pdf.

5.- Barrington KJ: Umbilical catheters in the newborns: effects of position of the catheter tip. Cochrane Database Syst Rev 2000; 2:CD00505.

6.- Hermansen $M$, Hermansen $M G$ : Intravascular Catheter Complications in the Neonatal Intensive Care Unit. Clin Perinatol 2005; 32: 141-56.

7.- Simanovsky N, Ofek-Shlomai N, Rozovsky K, ErgazShaltiel Z, Hiller N, Bar-Oz B: Umbilical venous catheter position: evaluation by ultrasaound. Eur Radiol 2011; 21: 1882-6.

8.- Darling JC, Newell SJ, Mohamdee O, Uzun O, Cullinane CJ, Dear PR: Central venous catheter tip in the right atrium: a risk factor for neonatal cardiac tamponade. J Perinatol 2001; 21 (7): 461-4.

9.- Nadroo AM, Lin J, Green RS, Magid MS, Holzman IR: Death as a complication of peripherally inserted central catheters in neonates. J Pediatr 2001; 138 (4): 599-601.

10.- Schoonakker BC, Harding D: Radiological signo f long line in the ascending lumbar vein. Arch Dis Child 2005; 90 (9): 982. 